\title{
PSICOLOGIA E FORMAÇÃO: O OLHAR DO CAÇADOR*
}

\author{
José LeON Crochík \\ Universidade de São Paulo, São Paulo, São Paulo, Brasil
}

\begin{abstract}
Resumo: Este texto teve como objetivo analisar a formação do indivíduo, sob a perspectiva da Teoria crítica da sociedade, dando ênfase a questões psicológicas e culturais. Para isso, utilizou do enredo do filme $A$ caça, de Thomas Vinterberg, exibido em 2012, para discutir quatro temas por ele suscitados: "a frieza violenta"; "a agressão justificada"; "a preservação das relações humanas"; e "a culpa dos outros".

PalavaAs-chave: Teoria crítica da sociedade. Formação. Psicologia.
\end{abstract}

INTRODUÇÃO

O filme dinamarquês $A$ caça, de Thomas Vinterberg, de 2012, tem como personagem central um professor de educação infantil de uma pequena cidade. Uma aluna sua, filha de um casal de amigos, vê imagens de genitália masculina, exibidas por seu irmão mais velho e um amigo desse. Um dia, seus pais brigam e o professor a leva para a escola; ela Ihe dá um beijo nos lábios, ele a afasta e pede que brinque com seus colegas; ela, (bem provável) inspirada pelas imagens que vira e sentindo-se rejeitada pelo professor, diz para a diretora que ele se exibira sexualmente a ela. Outros alunos também fazem um relato semelhante e o professor é afastado de suas atividades docentes. Ele é preso, porém absolvido da acusação, uma vez que as crianças disseram haver porão, inexistente, na casa do professor, onde ele fazia o indevido, segundo elas. Apesar de sua liberação, não só por falta de provas, mas também pela invenção desmentida sobre o porão, seus ex-amigos companheiros de juventude - e outros moradores da cidade continuaram a mantê-lo à distância. Um dia, ao fazer compras no supermercado, pedem-lhe

\footnotetext{
* Artigo recebido em 1/6/2013 e aprovado em 15/8/2013.
} 
que não volte lá; ele insiste e é agredido. "Não se bate nas pessoas", exclama. Dias depois, após uma discussão com seu amigo na igreja, é comemoração de Natal, e eles voltam a se relacionar bem.

Um costume prestigiado na cidade é a caça; ser reconhecido como caçador parece mesmo ser o limiar para a vida adulta; seu filho passa por esse ritual e, ao caçar com amigos e com seu filho, um tiro quase o atinge. Aparece a imagem sem nitidez de quem atirou se afastando; logo, não há dúvidas: o tiro fora intencional. Como o título promete, o caçador se torna presa.

Para a discussão a seguir, destaco quatro temas que se entrelaçam, suscitados por esse filme e associados à compreensão da Teoria crítica da sociedade sobre a formação, sobretudo em seus aspectos psicológicos: 1) frieza violenta - a reação fria, contida e, no entanto, acusatória de seus "amigos" que parecem prestes a "explodir", mas, a princípio, não o agridem fisicamente, só o mantêm afastado, de forma decidida; 2) agressão “justificada” - as agressões físicas contra ele e contra seu filho, que não são contidas; 3 ) preservação das relações humanas - o comentário que faz ao ser agredido: "não se bate nas pessoas"; e 4) a culpa dos outros - a acusação que persiste apesar de sua inocência.

\section{A FRIEZA VIOLENTA}

A formação do indivíduo para os autores da Teoria crítica da sociedade é a realização da própria cultura, é seu objetivo, mesmo porque a cultura humana só se preserva pela diferenciação individual. Formação individual é natureza transformada pela cultura; nesse sentido, a cultura é a expressão da natureza humana. Pela cultura, os indivíduos podem expressar seus sofrimentos, seus desejos, suas expectativas; quanto mais diversificados forem os instrumentos culturais para essa expressão, mais o indivíduo pode se conhecer e, assim, buscar os objetos propícios a evitar seus sofrimentos e a realizar seus desejos.

A natureza humana, no entanto, é conflitiva; preservar e destruir os objetos e a si próprio é consideração que está presente na análise de Kant (1986), expressa como sociabilidade insociável, e na discussão desenvolvida por Freud (1986) sobre o confronto entre as pulsões eróticas e as pulsões de morte. Adorno (1995b) indica a presença do mal-estar assinalado por Freud em relação à civilização que, ao se desenvolver, também amplia a tendência anticivilizatória.

O professor/caçador do filme é quem educa as crianças, ajuda a tornálas civilizadas e, ao mesmo tempo, persegue animais; porque o homem não deve ser caçado, os animais tomam seu lugar. O sacrifício da própria natureza 
se fortalece no sacrifício de outros animais. O controle de si mesmo, necessário para a caça, exige o "não se diferençar da natureza", o "fingir-se de morto", a própria frieza: o caçador deve - atento, imóvel e oculto - observar sua presa, segui-la com os olhos, mantendo todo o restante de seu corpo imóvel. Os "amigos" e colegas do professor o mantêm firmemente afastado, prontos a atacá-lo, mas receando-o como "caçador". A distância mantida pela visão a que o professor deve obedecer tenta controlar o que o ameaça; assim, a visão não só mantém a distância como afasta o perigo.

Conforme Horkheimer e Adorno (1985), a visão e a audição mantêm o outro à distância, em contraste com o olfato que é um sentido proximal. A formação burguesa privilegia as primeiras e nutre, no mínimo, uma ambiguidade em relação aos sentidos proximais: olfato, paladar e tato; um odor, um alimento, um contato com a pele são imediatamente agradáveis ou não, em contraste com a visão e a audição que preservam quem nós somos, mas obstam a experiência que não pode prescindir da proximidade. Nas técnicas psicológicas empresariais, utilizadas para gerar confiança entre colegas, pede-se que os olhos sejam vendados ou fechados: se para confiar os olhos devem se fechar, os olhos abertos são desconfiados.

Certamente, a leitura do olhar não só permite a experiência, mas também suscita os sentidos proximais. O olhar compreensivo acolhe, ao contrário daquele que desvia os olhos ou que atravessa o olhar do outro como comando que pede a obediência. O olhar do caçador espreita. $\mathrm{O}$ olhar temeroso atrai o predador, que percebe o medo que fragiliza; o olhar persecutório persegue o que teme.

Na cidade grande, a prostituta, segundo Benjamin (1989), deve desdobrar seu olhar: procura por seus clientes - "olho no olho" - e atenta, à distância, a polícia. Logo, o olhar citadino é dividido, assim como o do civilizado: espreita a presa e o predador. Mesmo a audição cede em relação à visão nas cidades grandes, isso é, na civilização. Benjamin cita Simmel: "Quem vê sem ouvir, é muito mais [...] inquieto do que quem ouve sem ver. Eis algo característico da [...] cidade grande. As relações recíprocas dos homens nas grandes cidades [...] distinguem-se por uma preponderância notável da atividade da visão sobre a audição" (1989, p. 142).

O filme, no entanto, localiza seus personagens em uma pequena cidade, na qual todos se conhecem; não há para onde escapar; os olhares se entrelaçam formando uma rede espessa que a todos prende; ao contrário da antiguidade, conforme Horkheimer e Adorno (1985), o desconhecido não é "estranho" ou "louco"; é previsível e controlado ainda por sua autovigilância.

A relação entre a visão e a audição também é tratada por Horkheimer e Adorno (1985) em sua análise da Odisseia, de Homero, no episódio das 
sereias. Os homens de Ulisses devem tapar seus ouvidos com cera para não ouvir-lhe o canto; devem olhar fixamente para frente: o canto das sereias aproxima o passado esquecido, marca da pátria perdida. Ulisses pode ver e ouvir, não pode ir ao encontro do que encanta: perde a vida ao preservá-la; o mesmo ocorre com a frieza.

Essa frieza, necessária ao caçador (e também para a sobrevivência da presa), ocasiona certo prazer. Se algo que é planejado consegue ser bem efetivado, gera a sensação de onipotência; quando isso ocorre, a sensação de poder sobre a própria vida e a dos outros recobre a sensação contrária e mais verdadeira: a impotência. Claro, o poder sobre a natureza é fundamental para a autoconservação, como discorrem Horkheimer e Adorno (1985); eles também destacam que sua necessidade é histórica, não essencial ao homem: uma sociedade de abundância de produção pode dispensar o poder.

O indivíduo burguês, para sua sobrevivência, deve desenvolver a frieza; como essa, no entanto, rivaliza com o carecimento de se estar com o outro, o conflito entre Eros e as pulsões da morte é inevitável no mundo burguês. A superação desse conflito ocorre com a superação da necessidade da dominação, anacrônica em uma sociedade de produção abundante; por isso, é notável que o diretor do filme seja oriundo da Dinamarca, um dos países mais desenvolvidos.

A desconfiança em relação ao personagem do filme o mantém à distância; e sua marginalização é o preço que paga por algo que não fez; a suspeita, a acusação se confunde com o ato do delito, o que é próprio do pensamento mágico, no qual coisa e palavra não se separam. No caso, o fato de o personagem poder ter cometido o crime já o torna criminoso. A distância necessária para o julgamento se transfere para a distância social e se ausenta desse julgamento. Esse, então, perde a distância necessária para não se fazer um julgamento imediato, e a prisão simbólica, dada pelo afastamento, tornase sua função: a de impedir a possível violência que o suspeito poderia vir a desencadear; assim, no entanto, a violência recai sobre o suspeito.

\section{A AGRESSÃO "JUSTIFICADA"}

Se a hostilidade ao personagem é constante na maior parte do filme, há também agressões físicas entre os personagens; a maioria das que foram dirigidas ao personagem e a seu filho tem como objetivo mantê-los afastados e revidar. Quando se dá o revide, parece não haver limites, como ocorre no supermercado, onde o professor leva diversos socos do açougueiro; o agressor pretende que ele não venha mais a seu comércio. Algo semelhante acontece quando um dos ex-amigos do professor agride seu filho sem parar, após esse 
ter cuspido na menina que denunciara seu pai; os amigos do agressor têm de segurá-lo. Esses ataques são feitos com uma raiva que se supõe justificada, parecendo extrapolar tal alegação. Há algo mais que é extravasado nesses atos, mais que o prolongamento da ordem verbal não cumprida: "afaste-se". O suposto delito, no entanto, é julgado tão grave, que mesmo a violência "justificada" parece desproporcional: se, de fato, o professor se exibiu sexualmente para uma menina de cinco anos, a raiva que isso acarreta - tendo em vista a proteção e os cuidados que devotamos às crianças - não se extingue nas agressões feitas ao professor. Em contrapartida, nas duas ocasiões em que o personagem agride fisicamente, uma o comerciante e outra seu amigo, a raiva se expressa também justificada, uma vez que tem como objetivo específico o restabelecimento de seus direitos: fazer compras no supermercado e não continuar a ser suspeito de algo que não fez.

A violência "justificada" é expressão das regras e leis a serem cumpridas; representa o policial que dela se utiliza em nome da sociedade, para manter a ordem social ou interesses particulares. É curioso que, no filme, a polícia não aparece praticando agressões físicas; os ex-amigos fazem, eles próprios, esse papel. Essa violência legitimada e legalizada é exercida em nome do direito, mas esse é usurpado quando, conforme enfatizado antes, o acusado é punido antes e depois de ser provada a sua inocência no ato delituoso. Direito e justiça, na sociedade burguesa, não necessariamente coincidem.

Essa espécie de suspensão da existência da vida do suspeito em função de algum possível delito expressa, como já ressaltado, o que de anticivilizatório está contido em nossa sociedade que, à medida que avança, fortalece o seu contrário; algo afirmado por Freud (2006) e circundado por Horkheimer e Adorno (1985). Há uma malha extensa e densa formada pelas regras, da qual não conseguimos escapar. Mas se a violência deve ser justificada, a que não o é sai "pelas portas dos fundos" e se aloja clandestinamente nos próprios atos "civilizatórios". É dessa forma que podemos pensar acerca da utilização da tecnologia com fins destrutivos, da qual a câmera de gás utilizada nos campos de concentração nazistas é marca. As pessoas são eliminadas pelo estado de forma asséptica, como se não se tratasse de extermínio de pessoas, mas de detritos humanos que não servem mais sequer ao trabalho.

O ostracismo a que são condenados os suspeitos de crimes, os prisioneiros, assim como os que não servem mais para o trabalho indica não somente a sobrevivência do fascismo, mas que esse tem sido, até o momento, característica inerente à sociedade burguesa. Cabe aqui uma palavra acerca desse mundo burguês: ele remete ao burgo, à cidade, à civilização; não é, pois, redutível unicamente ao capitalismo. Segundo Horkheimer e Adorno (1985), 
se Ulisses - personagem da Odisseia de Homero - foi o protótipo do indivíduo burguês e se seu mundo o arquétipo do mundo burguês, só conhecemos, até então, essa forma de vida. Mesmo o socialismo soviético, criado e desfeito no século XX, é derivado do pensamento e das relações burgueses; não é outra a crítica que esses autores fazem a tal socialismo: por terem tornada eterna a necessidade vinculada ao trabalho, perderam o reino da liberdade. $O$ apreço ao trabalho como uma necessidade não indica a liberdade, mas, sim, seu contrário; sua origem é burguesa e sua manutenção não consegue superá-la.

O crime do qual é suspeito o professor - ter se exibido sexualmente para uma menina de cinco anos, aluna da escola -, a que denominamos "exibicionismo", também deve ser pensado. Já foi demonstrado pela Psicanálise que as crianças não são assexuadas - no filme, a menina beija o professor nos lábios; e que a visão do corpo do outro provoque algum dano psicológico é algo que, segundo Adorno (1969), deve ser provado. Nesse sentido, é importante notar que a aluna retira a ideia da acusação de imagens que seu irmão mais velho lhe mostrara em um tablet. Note-se também que, no início do filme, os amigos do professor tomam banhos nus em um lago. Por que, então, o tabu sobre o corpo do homem permanece? Aparece o conflito entre a proibição da exibição do corpo e o desejo de vê-lo, acarretado por essa proibição.

Freud (1943) defende que a repressão da curiosidade sexual pode gerar transtornos sexuais e psíquicos; Adorno (1995b) indica que a repressão faz com que o reprimido retorne sob a forma de violência. Por que a repressão sexual ainda é necessária? Poder-se-ia pensar que, no caso, não se trata de repressão sexual, mas coibir o abuso sexual; cabe, no entanto, enunciar a contradição: o exibicionismo sexual é proibido e os corpos nus são mostrados a todo o momento, sobretudo pelas diversas mídias.

Adorno (1969), ao analisar a perseguição às prostitutas e aos homossexuais, defende a hipótese de que manifestações sexuais foram permitidas com a liberação sexual, mas não o impulso sexual; esse teria perdido sua função obscena, subversiva. Da análise anterior da violência exibida no filme, parece que não só a sexualidade deve ser justificada, mas também a violência; aliás, é a não observância dos tabus sexuais que gera essa violência. A sexualidade e a agressão humanas, na sociedade administrada, também devem ser administradas.

\section{PRESERVAÇÃO DAS RELAÇÕES HUMANAS}

A frase dita pelo personagem - após ter sido agredido no supermercado: "Não se bate nas pessoas" - foi dita com raiva e se constitui em repri- 
menda. Coerente com o restante do filme, toda forma de violência física deve ser evitada; essa pode se voltar para os animais caçados, que não oferecem nenhum perigo aos homens. Poder-se-ia pensar em uma espécie de sublimação, como a define a psicanálise: o alvo da pulsão foi alterado para algo consentido socialmente. Ressalta-se que, no filme, ser caçador parece representar a passagem da adolescência para a vida adulta, momento também no qual a sexualidade pode ser exercida em sua função reprodutiva e consentida.

Na caçada, o caçador deve se ocultar no habitat da presa, de tal maneira a não se diferenciar da natureza. Não se deve mesmo fazer nenhum ruído que denuncie sua presença; nas palavras dos frankfurtianos: "fingir-se de morto". Se o desenvolvimento humano implica na diferenciação crescente da natureza, na caçada, essa diferenciação deve, aparentemente, ser negada, tal como Ulisses o fez quando nega seu nome e se nomeia de "ninguém" para ludibriar seu adversário, conforme ressaltam Horkheimer e Adorno (1985).

A essa técnica de ocultação, que envolve também a roupa utilizada, se soma a arma a ser utilizada, que deve ser silenciosa em seu preparo; ela abate o animal à distância e evita qualquer contato físico, qualquer possibilidade de se perceber o sofrimento da vítima, tal como ocorreu nos assassinatos nas câmaras de gás e nos realizados pelos atuais aviões não tripulados, guiados por controle remoto. A falsa indiferenciação da natureza, contida no "fingirse de morto", integra a completa indiferença (diferenciação plena como alienação) com a presa. Essa é mero exemplar que, conforme Horkheimer e Adorno (1985), corre no labirinto científico de um lado para outro, no sacrifício moderno para a sobrevivência da espécie humana (permitida pelas descobertas da ciência) e, ao mesmo tempo, para o controle dos homens; esse também aprendido por meio do controle que se faz sobre os animais.

Para os frankfurtianos, com a substituição gradual da vítima sacrificial - o filho que pode ser substituído pelo cervo -, dá-se início à indiferença em relação a quem deve ser sacrificado: todos passam a representar a espécie, são seus exemplares. Segundo esses autores, devido a uma única diferença entre o senhor e o objeto, entre a cultura e a natureza, todas as outras distinções são negadas. Os homens não devem se distinguir entre si, e os seres da natureza também não. O sacrifício da presa na caçada é afirmação do poder do senhor que também deve ser exercido pelos indivíduos contra si mesmos e contra os outros; não é somente a natureza que é reprimida, mas o desejo que dela provém e nos torna humanos, quando pode ser expresso na e pela cultura.

"Não se bate nas pessoas" diz respeito à sua dignidade e que deve ser distinta da que se volta aos animais: os homens não devem ser alvo da caçada; o que é caçado nos homens, no entanto, é a natureza que tentamos 
sufocar. Não se trata de defender a liberdade que destrói os outros, mas de defender que a sexualidade, quando livre, não alimenta a violência e se converte em preservação dos objetos amados. O professor, ainda mais de crianças pequenas, trata de auxiliar a desenvolver em seus alunos os hábitos necessários ao convívio pacífico e harmônico entre todos; trata de converter a natureza dispersa em civilização: à pulsão, a cultura oferece objetos que permitem a diferenciação do próprio indivíduo.

Segundo Freud (2006), o amor não é universal, isso é, não pode ser dirigido a todos os indivíduos de forma indistinta, pois, caso contrário, esses não serão dotados de singularidade por quem os ama. Para todos os homens, contudo, é possível dirigir o respeito e não a agressão. $\mathrm{O}$ amor burguês, o mais avançado que conhecemos, é fusão entre as pulsões sexuais e as pulsões sexuais inibidas em sua finalidade. Essas últimas são responsáveis pela singularização expressa pelo carinho, pela ternura, o que permite preservar o objeto da paixão após a satisfação da pulsão sexual. Se estiverem presentes apenas as pulsões inibidas em sua finalidade, há a amizade; se predominarem unicamente as pulsões sexuais, o objeto até pode ser delineado culturalmente, mas não é singularizado.

As experiências que são a matéria-prima da formação consistem, pois, nas relações do sujeito com o que não é distinto de si. Isso não significa que nessas relações o sujeito não se apresente na representação que faz do objeto com o qual se relaciona; ao contrário, conforme Horkheimer e Adorno (1985), o sujeito projeta sobre o objeto o que imagina que esse seja e o faz, seguindo Freud (2006), mediado por seus desejos do que precisa que o outro seja. A experiência finaliza quando há o máximo de distinção possível entre essa representação do objeto e o que ele é; a experiência com o objeto permite diferençá-lo de nossa projeção e entender que ele não é o que desejaríamos que fosse. A idealização do objeto é o projétil que o atinge e o aprisiona; se não há morte natural, como na caçada, há morte simbólica; o objeto idealizado deve se comportar segundo o ideal.

A frieza e a violência contidas contra os animais na caçada fazem injustiça aos animais e aos homens; aos primeiros, por serem reduzidos à mera espécie, indiferentes para nós; aos últimos, por terem sua natureza negada, assim como seus desejos, que só podem ser realizados de forma contida e não exuberante.

\section{A CULPA DOS OUTROS}

Se, seguindo Freud (1975), o crime alivia a (in)consciência de culpa de alguns indivíduos, a responsabilização dos outros pela concretização de 
nossos desejos inconfessos realiza, inconscientemente, de forma vicariante, esses desejos e, ao contrário, reforça os guardiões que os impedem de se tornarem conscientes.

No filme, mesmo não havendo provas de seu delito, o professor continua suspeito; mais do que isso, foi condenado. Alguém precisa ser sacrificado pela proibição do desejo a todos. Como não há o reconhecimento em cada qual dos desejos universais que não podem, em nossa cultura, sequer ser expressos, alguns devem apresentá-los e serem responsabilizados por isso; assim como o cristianismo defende que Cristo se sacrificou por toda a humanidade, os sacrifícios ainda são necessários.

A identificação negada com o desejo expresso no ato do criminoso divide a humanidade em duas partes: os que seguem os tabus e os que os negam. Os tabus mesmos quase não são pensados, nem mesmo em relação à diversidade de suas funções; essas, como regras de proibição, podem ter como objetivo a sobrevivência da espécie, sua diferenciação progressiva da natureza, e/ou a justificação da dominação de uma classe social, uma casta, um grupo sobre outros. O reconhecimento de um desejo proibido e de sua expressão, como defende a psicanálise, libera-o de sua maldição - a repetição - e ele pode ser convertido em outra destinação. Já a sua manutenção e a não reflexão constituem causa da violência, de um lado, dos que procuram romper o tabu e, de outro, da sociedade contra os que o violam. De um lado, aqueles que se sentem oprimidos, ou que falam em seu nome desprezam, desrespeitam os tabus e, por conseguinte, aqueles que os seguem. De outro lado, a violência, em nome da justiça, é vingança "civilizada" dos que transgridem esses tabus.

No ritual de transição entre a adolescência e a vida adulta, pelo qual passa o filho do professor ao se tornar caçador, há identificação com os ideais representados nessa atividade, alguns dos quais foram comentados anteriormente neste texto: a dominação à distância da natureza; a observação dos outros e o controle sobre si; a habilidade de se fingir de morto. No tiro que quase atinge o professor, durante a primeira caçada de seu filho, há a identificação negada: a natureza - representada por pulsões"não dominadas" - que não pode se expressar.

Segundo Adorno (1995a), os alunos buscam nos professores o que neles há de natureza "não dominada", que se expressa em seus maneirismos e esquisitices; já há razão, portanto, do surgimento de raiva contra o que representa o professor; se esse é suspeito de um crime, que deixa antever seus impulsos não domesticados, essa raiva ganha forma na violência contra ele. Em sua figura, os extremos se encontram: conversão da natureza em civilização que se expressa espontaneamente. Conforme esse autor, há 
certa ambivalência em relação ao professor: ele é respeitado e desprezado. Respeitado pelo saber que supostamente tem; desprezado por parecer frágil e não ter as habilidades necessárias para a sobrevivência cotidiana, nem para a realização dos desejos mundanos. Salienta-se, também, a tendência anti-intelectualista própria de uma sociedade fascista, que despreza tudo o que possa ser subjetivo, inclusive o pensamento. No filme, tal ambivalência é extremada, pois há a suspeita de que aquele que deveria representar os mais altos valores da convivência e ensinar a nossos filhos abusa deles.

A caça, conforme afirmam os personagens, torna o menino um homem e o homem um menino; o primeiro deve aprender a desenvolver as características antes referidas neste texto; o adulto pode ter atividades que, destituídas de quaisquer funções, mantêm os controles sobre a natureza externa e sobre si. O jovem aprende; o adulto mantém e fortalece o que aprendeu.

No filme, o crime é de natureza sexual. As suspeitas de crimes que recaem sobre aqueles que têm uma vida sexual moralmente condenada são destacadas por Adorno (1969); ele defende que a justiça civilizada dê mais atenção a crimes sexuais e aos contra a propriedade, do que àqueles que atentam contra a vida. Horkheimer e Adorno (1985) indicam que, com a propriedade fixa, dominação e trabalho se separam; mostram também que o proprietário pode saber da existência do desejo e ser amarrado (o episódio das sereias na Odisseia de Homero) para que esse não se realize - tal como a violência contida do civilizado, a sexualidade também deve ser delimitada; já seus homens - os trabalhadores - devem desconhecer até o desejo.

No filme, há de se pensar no beijo que a pequena aluna deu no professor e na identificação dos colegas com ela, ao indicar que algo semelhante ao que ela relatara aconteceu também com eles. Na ação erótica da menina, há o desmentido da sedução dos filhos pelos pais, ou das crianças pelos adultos; não que essa sedução não exista (não só existe, como não é pequena a frequência de filhos (as) estuprados (as) pelos pais (Cf. CROCHÍKe FERNANDES, 2011). Por certo, a sedução dos filhos pelos pais não se compara com a dos pais pelos filhos; no primeiro caso, há delito grave; no último, não. No entanto, não foi de pouca relevância Freud ter chamado a atenção para os desejos infantis, uma vez que tal sedução também pode ser ocasionada pela criança; essa descoberta é base do importante conceito psicanalítico referente ao Complexo de Édipo - os filhos desejam eroticamente seus pais. Isso não ter sido aventado como hipótese pelos acusadores do professor revela a presença da repressão sexual em um mundo considerado de plena liberdade sexual. Na identificação de seus colegas com a suposta situação da pequena aluna parece estar presente a frágil constituição do"eu", compreensível nessa fase da 
vida, mas, ao que parece, não considerada pelos acusadores que acreditaram mais nas crianças do que em seu professor. É curioso como a sexualidade infantil é negada, a pouca capacidade de compreensão, a dificuldade de separar fantasia de realidade, também. Claro, as crianças poderiam estar mencionando o que efetivamente ocorrera; seria autoritário desconsiderar o que têm a dizer, pois, com certeza, compreendem mais do que pensamos ou queremos que compreendam; porém isso não significa desconsiderar o que o professor poderia relatar.

Sobre o que foi indicado no parágrafo anterior, cabe destacar também que quando a aluna quis desmentir o que disse, os adultos não permitiram, julgando que dada a dificuldade da recordação, ela tentaria negá-la; é somente ao final do filme que seu pai, já confiando em seu amigo, acredita nela.

Passado um ano, na festa em que o filho do professor ganha a permissão para se tornar caçador, alguns amigos, amistosamente, os acolhem, a ele e a seu filho, denotando que acreditaram em sua inocência; outros, de maneira mais fria, o que indica que nem todos confiaram. Considerando-se a propriedade mediando todas as relações na sociedade burguesa, não é difícil entender que a desconfiança é a sua base. Se a confiança explícita une os homens em seu convívio para o afeto e para o trabalho, o seu contrário não é menos presente, só que oculto, e vai, de modo imperceptível, juntando indícios contra os outros. Quando ocorre um incidente tal como o do filme, essa memória"marginal" torna-se central, e tudo aquilo que a experiência deu base para uma sólida relação se desfaz. Se todos - menos o filho e um de seus amigos - abandonam o professor, é porque toda experiência que tiveram com ele não foi suficiente para que pudessem ouvi-lo e acreditar no que dizia.

Se, para alguns indivíduos, cometer um crime alivia a culpa que sentem sem saber o porquê - indicando que o criminoso já o é antes de cometer o crime (FREUD, 1975) -, para a maioria das pessoas, em uma sociedade em que o controle mútuo é onipresente, como a nossa, a acusação do outro já o espreita, antes que cometa qualquer crime, ou que seja denunciado por ter cometido um.

POR FIM...

Por certo, os aspectos do filme que foram destacados neste texto não Ihe fazem justiça: ele tem muito mais conteúdo e forma a serem analisados. Neste ensaio, a ênfase dada à parte do conteúdo não é, necessariamente, proposta pelo diretor do modo como a análise aqui efetuada ressaltou. Esse filme, no entanto, suscitou temas que são propícios à formação do indivíduo 
burguês: a frieza, a violência "justificada", a preservação das relações humanas e a atribuição da culpa aos outros; nesses temas, enfatizei a dominação da natureza própria e alheia, os rituais, os tabus.

Do filme, não foi possível retirar o porquê de o fato contado ter ocorrido, mas para a Teoria crítica da sociedade, a concomitância da existência da civilização e da barbárie - ou, mais precisamente, a presença constante dessa última na primeira - não é algo inerente a essa civilização, e nem é insuperável.

A formação burguesa, mediada pela propriedade, constitui-se por um domínio psicológico sobre o "eu" que o substitui; a crítica a esse domínio feita por uma "psicologia negativa" atrelada a uma teoria crítica da sociedade, que a desenvolveria, poderia ser capaz de desvelar o que tem sido feito de nós e a nós em nome de uma sociedade dita justa, porém injusta em sua base. No seu lugar, a psicologia e a educação existentes têm operado no sentido de auxiliar na formação de pseudoindivíduos, como os retratados no filme analisado.

\section{PSYCHOLOGY AND EDUCATION: THE GAZE OF THE HUNTER}

АвттRAст: this text set out to analyze the formation of the individual, from the perspective of the Critical Theory of Society, while highlighting psychological and cultural issues. To do so, it uses the plot of Thomas Vinterberg's movie The Hunt, shown in 2012, to discuss the four themes it raises: violent callousness, justified aggression, the preservation of human relationships, and the fault of others.

KEYWORDS: Critical Theory of Society. Education. Psychology.

\section{PSICOLOGÍA Y FORMACIÓN: EL OJO DEL CAZADOR}

RESUMEN: Este texto pretende analizar la formación del individuo, bajo la perspectiva de la teoría crítica de la sociedad, enfatizando en los aspectos psicológicos y culturales. Para eso, se valió del argumento de la película 'La caza', de Thomas Vinterberg, exibida en 2012, para discutir cuatro temas por él planteados: 'la indiferencia violenta'; la 'agresión "justificada"'; 'la preservación de las relaciones humanas'; y'la culpa de los otros'.

Palabras Claves: Teoría crítica de la sociedad. Formación. Psicología.

\section{REFERÊNCIAS}

ADORNO, T. W. Los tabús sexuales y el derecho hoy. In: Intervenciones: nueve modelos de critica. Trad. Roberto J. Vernengo. Caracas: Monte Ávila, 1969. p. 91-115. 
. Tabus acerca do magistério. In: Educação e emancipação. Trad. Wolfgang Leo Maar. Rio de Janeiro: Paz e Terra, 1995a. p. 97-117.

. Educação após Auschwitz. In: Educação e emancipação. Trad. Wolfgang Leo Maar. Rio de Janeiro: Paz e Terra, 1995b. p. 119-138.

BENJAMIN, W. Sobre alguns temas em Baudelaire. In: Charles Baudelaire: um lírico no auge do capitalismo. Trad. José Martins Barbosa e Hemerson Alves Baptista. São Paulo: Brasiliense, 1989. p. 103-149.

CROCHÍK, J. L.; FERNANDES, A. M. (Org.). Violência sexual contra crianças e adolescentes na cidade de São Paulo. 1. ed. Campo Grande: Editora da UFMS, 2011.

FREUD, S. La moral sexual "cultural"y la nerviosidad moderna. Obras completas. Buenos Aires: Editorial Americana, 1943. p. 31-55.

. O ego e o id. Pequena coleção das obras de Freud. Rio de Janeiro: Imago, 1975.

. Psicología de las masas y análisis del yo. In: Obras completas. Tomo XVIII. Trad. J. L. Etcheverry. 5. reimpressão. Argentina: Amorrortu, 1993. p. 63-136.

. O mal-estar na civilização. In: SALOMÃO, S. (Org.). Edição standard brasileira das obras psicológicas completas de Sigmund Freud. v. XXI. Rio de Janeiro: Imago, 2006. p. 67-150.

HORKHEIMER, M.; ADORNO, T. W. Dialética do esclarecimento: fragmentos filosóficos. Trad. Guido Antônio de Almeida. Rio de Janeiro: Jorge Zahar, 1985.

KANT, I. Ideia de uma História Universal de um ponto de vista cosmopolita. São Paulo: Brasiliense. 1986.

VINTERBERG, T. A caça. Dinamarca: Califórnia Filmes, 2012.

José LeON CROCHík é docente do Instituto de Psicologia da USP; bolsista de Produtividade em Pesquisa do CNPq.

E-mail: jlchna@usp.br 